\title{
Psychiatric co-morbidity with type 1 and type 2 diabetes mellitus
}

\author{
T. Coclami and M. Cross ${ }^{1}$
}

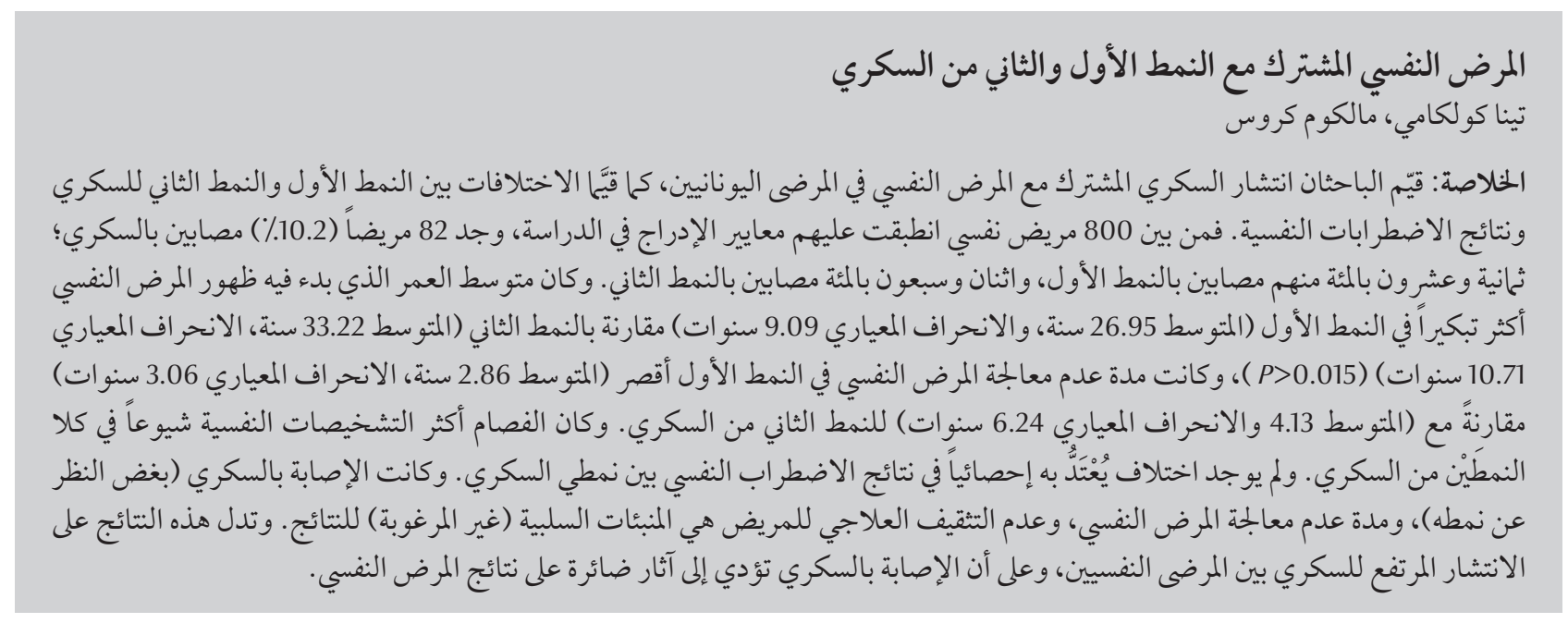

ABSTRACT We evaluated the prevalence of diabetes comorbidity in Greek psychiatric patients, differences between type 1 and type 2 diabetics and the outcome of psychiatric disorder. Of 800 psychiatric patients meeting our inclusion criteria, $82(10.2 \%)$ had diabetes mellitus; $28 \%$ type 1 and $72 \%$ type 2 . The mean age at onset of mental illness was earlier for type 1 diabetics (mean 26.95, SD 9.09 years) than type 2 (mean 33.22, SD 10.71 years) $(P<0.015)$ and the duration of untreated mental illness was shorter (mean 2.86, SD 3.06 years compared with mean 4.13, SD 6.24 years for type 2 diabetics). Schizophrenia was the commonest psychiatric diagnosis in both types of diabetes. There was no significant difference in outcome of psychiatric disorder between the 2 types of diabetics. Existence of diabetes mellitus (regardless of type), duration of untreated mental illness and lack of patient therapeutic education were negative predictors of (unfavourable) outcome. These findings provide evidence of a high prevalence of diabetes in psychiatric patients and that having diabetes has an adverse effect on outcome of psychiatric illness.

\section{Comorbidité psychiatrique et diabète de type 1 et de type 2}

RÉSUMÉ Nous avons évalué la prévalence de la comorbidité du diabète chez des patients grecs atteints de troubles psychiatriques, les différences entre les diabétiques de type 1 et de type 2 et l'évolution des troubles psychiatriques. Sur 800 patients atteints de troubles psychiatriques remplissant nos critères d'inclusion, $82(10,2 \%)$ souffraient de diabète. Parmi eux, $28 \%$ présentaient un diabète de type 1, et $72 \%$ un diabète de type 2. L'âge moyen d'apparition du trouble mental chez les diabétiques de type 1 était inférieur (moyenne 26,95; E.T. 9,09 ans) à l'âge moyen d'apparition chez les diabétiques de type 2 (moyenne 33,22; E.T. 10,71 ans) $(P<0,015)$; la période sans traitement du trouble mental était également plus courte chez les diabétiques de type 1 (moyenne 2,86; E.T. 3,06 ans) que chez les diabétiques de type 2 (moyenne 4,13; E.T. 6,24). La schizophrénie était le diagnostic le plus fréquent dans les deux types de diabète. Aucune différence significative dans l'évolution du trouble psychiatrique n’a été observée entre les deux types. La présence d’un diabète (quel que soit le type), la période pendant laquelle le trouble mental n'était pas traité et l'absence d'éducation thérapeutique du patient étaient des facteurs prédictifs négatifs d'évolution défavorable. Ces résultats prouvent la prévalence élevée du diabète chez les patients souffrant de troubles psychiatriques et l'effet néfaste du diabète sur leur évolution. 


\section{Introduction}

The incidence of diabetes mellitus in psychiatric patients has been found to be 2 to 8 times higher than in the general population [1-3].

A 10\% frequency of diabetes mellitus in patients with bipolar disorder (manic and mixed subtypes) has been reported [2]. A study in the United States based on medical records found a prevalence of $26 \%$ for diabetes inpatients with bipolar I disorder [4]. A Canadian study found a prevalence of $11.7 \%$ of diabetes mellitus in a community-based sample of individuals diagnosed with bipolar disorder [5]. Such figures are significantly greater than the $4 \%$ frequency expected in the general population [6].

Other studies suggest that diabetes doubles the risk of depression [7]. The adverse influence of depression on the course of diabetes has been discussed extensively [8]. A randomized control trial found improvements in depression concomitant with improved diabetic control [9]. This link to metabolic control gives depression a unique importance in diabetes.

The association between diabetes and schizophrenia has been a longstanding consideration for those working in the fields of medicine and psychiatry. "Diabetes is a disease which often shows itself in families in which insanity prevails" [10]. This observation reported in 1867 , uncomfortably expressed by today's standards, is supported by a more recent study that found that $15.8 \%$ of a patients diagnosed with schizophrenia also had a diagnosis of diabetes mellitus [3]. Other literature suggests that type 2 diabetes is 2 to 4 times more prevalent in people with schizophrenia compared to the general population $[11,12]$.

As evidenced by a recent journal supplement devoted entirely to schizophrenia and diabetes [13], research investigating the comorbidity of diabetes and mental illness is pertinent. However, differences between type 1 and type 2 diabetics with psychiatric disorders have rarely been considered by previous research.

We therefore sought to i) evaluate the prevalence of the comorbid diabetes in a sample of Greek psychiatric patients and (ii) determine if differences in demographic characteristics, clinical profile and outcome of psychiatric disorder in the sample were associated with type of diabetes.

\section{Methods}

\section{Sample}

Data were collected from all consecutive voluntarily and involuntarily admissions (3124patients) totheKastaliahellinikon Psychiatric Clinic in Athens in Greece during the study period 2001-2006. Inclusion criteria were: age $\geq 18$ years (to enable psychiatric diagnosis based on DSM-IV [14]); no treatment drop-out before completion of the inpatient treatment phase; and an absence of mental retardation, alcoholism or neurological illness.

Only the 800 (25.6\%) patients who fitted the selection criteria were evaluated for the presence of the comorbid condition of diabetes mellitus. A diagnosis of diabetes mellitus was based on clinical signs, as observed by a diabetologist, and a fasting venous plasma glucose (FPG) level >140 g/dL on at least 2 separate occasions during hospitalization. The cut-off of $140 \mathrm{~g} /$ $\mathrm{dL}$ was used to have a clear diagnosis is diabetes.

The final sample consisted of 82 (10.2\%) psychiatric patients who were found to have diabetes mellitus. This sample was further categorized on the basis of diabetes type ( 1 or 2 ), in order to facilitate the identification of any differences between the two types of diabetes and the demographic characteristics and clinical parameters of the patients.

All patients were known to the first author who was part of the team of clinicians that had supervised their treatment process.

\section{Measures}

Psychiatric diagnoses were based on DSM-IV [14] and resulted from clinical interview at admission of the patient to the psychiatric unit. Clinical interviews were designed to gather data about relevant clinical history, including treatment compliance and therapeutic education, current symptoms and sociodemographic characteristics.

Consistent with previous studies [15], duration of untreated mental illness (duration of untreated psychosis) was defined as the time from the onset of psychiatric illness (defined as the time period in which the patient first experienced the signs and symptoms of the diagnosed disorder) to the time when the patient received treatment.

Outcome of psychiatric disorder was measured in terms of the presence of relapse to a new episode, re-hospitalization over a 2-year follow-up period, and degree of symptom remission. Follow-up assessments were conducted by the same clinical team that treated the patients in the hospital. A 2-year follow-up period was chosen as the majority of new episodes occur within 2 years of remission [16]. Poor outcome was defined as the presence of relapse to a new episode or re-hospitalization over the 2-year follow-up period. A favourable outcome was defined as no relapse within the 2-year follow-up period.

Data obtained from the above measures were supplemented by information obtained from clinical records, referring and treating psychiatrists and interviews conducted with family members of the patients.

\section{Ethical issues}

All patients were informed about the nature of the research within the hospital and willingly gave their consent to participate. In fewer than 10 patients we used educational interventions, which according to the literature have 
been shown to improve understanding of study information in patients with psychotic and mood disorders $[17,18]$. Information sheets and preliminary interviews made it clear that the choice to consent or otherwise would have no bearing on the treatment offered.

The project ensured the anonymity of the subjects by replacing patient names with unique identifying numbers before the statistical procedures began.

\section{Statistical methods}

A secure computerized database was established and maintained throughout the study. Patient names were replaced with unique identifying numbers.

Statistical analyses were performed using the SPSS, version 10.0 for Windows. Data are presented as mean and standard deviation (SD) for continuous variables and frequencies for categorical variables. Differences between type 1 and type 2 diabetics were analysed by the Pearson chi-squared test for discrete variables (sex, education, marital status, employment status) and $t$-tests for continuous variables (age, age at onset of psychiatric symptoms, number of admissions, duration of untreated mental illness). Multiple regression analysis was used to determine the predictors of outcome of mental illness.

\section{Results}

\section{Demographics and prevalence}

Of the 800 psychiatric patients, 82 (10.2\%) had diabetes as a comorbid condition. Type 2 diabetes was the most prevalent type in $59(72 \%)$ patients while the remaining 23 (28\%) was classified as type 1 diabetes.

As reflected in Table 1 , type 1 diabetics were typically younger in age (mean 35.21, SD 10.72) than type 2 diabetics (mean 46.08, SD 9.01 years), a statistically significant difference $(t=$ $4.64, \mathrm{df}=80, P<0.0001)$. The mean age at onset of mental illness for type 1 diabetics was earlier (mean 26.95, SD 9.09 years) than for type 2 diabetics (mean 33.22 , SD 10.71 years $)(t=2.48, d f=80$, $P<0.015)$. The duration of untreated mental illness was shorter for type 1 diabetics (mean 2.86, SD 3.06 years) compared to type 2 diabetics (mean 4.13 , SD 6.24 years). The duration of untreated mental illness was positively correlated with the age of diabetics at study entry $(r=0.21, P<0.05)$, but not with their age at onset of psychiatric symptoms.

Table 2 gives the demographic characteristics of the patients with psychiatric illness and comorbid diabetes according to type of diabetes. There were no statistically significant differences between psychiatric patients with type 1 and 2 diabetes in terms of sex, education or marital status but there was a significant difference for employment with more patients with type 1 diabetes being unemployed $(P<0.03)$.

Table 3 shows that schizophrenia was the most prevalent psychiatric diagnosis in both types of diabetes ( $53.2 \%$ of psychiatric patients with type 1 diabetics had schizophrenia and $43.4 \%$ with type 2 had schizophrenia).

As regards timing of diagnosis, $49.3 \%$ of the patients ( $81 \%$ type 1 and $37 \%$ type 2 ) had been diagnosed with diabetes mellitus before their first psychiatric hospitalization. In $29.6 \%$ of type 1 patients the onset of diabetes was almost at the same time as the onset of mental illness, with diabetes preceding mental illness by less than 6 months. In $31.5 \%$ of type 2 patients, mental illness preceded diabetes onset by more than 4 years. This was a statistically significant difference between type 1 and type 2 diabetes $\left(\chi^{2}=36.46, \mathrm{df}=7, P<0.001\right)$.

\section{Outcome of psychiatric illness}

As regards readmissions, $34.6 \%$ of the patients had 3 or more admissions to any psychiatric hospital (33.3\% type 1 and $35.2 \%$ type 2 ), $16 \%$ had 2 admissions (14.3\% type 1 and $16.7 \%$ type 2 ) and $21.7 \%$ of type 1 and $13.6 \%$ of type 2 diabetics were readmitted at least once over the 12-month follow-up period. There were no significant differences between the 2 diabetes groups in the number of readmissions $(t=0.14, \mathrm{df}=$ $80, P>0.05)$.

The main reason for readmission was the patient's non-compliance with psychiatric medication (35\%). The second reason was poor diabetes control before the reappearance of a new mental illness episode (30\%). About half of the diabetics (52.2\% type 1 and $55.9 \%$ type 2 ) were readmitted to the hospital at some point in their lives. The majority of the type 2 diabetics (52\%) had poorer diabetes control during the relapse of their psychiatric illness.

As regards compliance, $41.4 \%$ of our patients were non-compliant with psychiatric treatment while $25.4 \%$ adhered to diabetes treatment (regular visits to the diabetologist and controlled blood glucose levels). Only 20\% type 1 and $8.5 \%$ type 2 patients had had any therapeutic patient education about diabetes.

Table 4 shows the results of the multiple regression analysis used to identify predictors of outcome within 2 years. Only the provision of therapeutic patient education was identified as a positive predictor of (favourable) outcome. The duration of untreated mental illness and the existence of diabetes (regardless of type) were negative predictors of (unfavourable) outcome of the mental illness.

\section{Discussion}

\section{Prevalence of diabetes comorbidity}

The present study confirmed the higher prevalence of diabetes in psychiatric patients (10.2\%) than found in the general population, adding weight to the proposition that this may be a universal phenomenon [3]. Epidemiological studies [19] have typically established higher prevalence rates $(15 \%-30 \%)$ of diabetes in psychiatric patients than 


\begin{tabular}{|c|c|c|c|c|c|}
\hline \multirow[t]{2}{*}{ Characteristic } & \multicolumn{2}{|c|}{ Type $1(n=23)$} & \multicolumn{2}{|c|}{ Type $2(n=59)$} & \multirow[t]{2}{*}{ Statistics } \\
\hline & Mean & SD & Mean & SD & \\
\hline Age (years) & 35.21 & 10.72 & 46.08 & 9.01 & $t=4.64, \mathrm{df}=80, P<0.0001$ \\
\hline $\begin{array}{l}\text { Age at onset of psychiatric } \\
\text { symptoms (years) }\end{array}$ & 26.95 & 9.09 & 33.22 & 10.71 & $t=2.48, \mathrm{df}=80, P<0.015$ \\
\hline Number of admissions & 2.34 & 1.66 & 2.42 & 2.46 & $t=0.14, \mathrm{df}=80, P>0.05$ \\
\hline $\begin{array}{l}\text { Duration of untreated } \\
\text { mental illness (years) }\end{array}$ & 2.86 & 3.06 & 4.13 & 6.24 & $t=-1.24, \mathrm{df}=75.68, P>0.05$ \\
\hline
\end{tabular}

$S D=$ standard deviation.

our investigation. This may be due to the fact that our sample consisted of inpatients only and therefore excluded those patients with milder psychiatric symptoms. In addition, the method of participant recruitment (e.g. formal diagnostic criteria, audit of medical records) may have eliminated a proportion of false positives that may have been included in studies conducted in more naturalistic, outpatient settings. Putting aside the magnitude of the prevalence, it is clear that our study, along with numerous others [1-3], highlights the disproportionate prevalence of diabetes in individuals with psychiatric diagnoses.

\section{Psychiatric diagnosis and diabetes comorbidity}

Schizophrenia was the most common psychiatric diagnosis with diabetes (both type 1 and type 2). This finding contrasts with reports that identified depression [19]. This difference may be accounted for by the fact that our sample was obtained from an inpatient psychiatric setting and therefore more likely to have more severe psychiatric conditions.

\section{Differences between type 1 and type 2 diabetes}

In our study, type 1 diabetes patients were more likely to be diagnosed with diabetes prior to their psychiatric hospitalization (81\%) and type 2 diabetes patients more likely to be diagnosed with diabetes after hospitalization (68\%). It has been suggested that, in the case of type 2 diabetes, one should consider the possibility of "neuroleptic-induced

\begin{tabular}{|c|c|c|c|c|c|}
\hline \multirow[t]{2}{*}{ Characteristic } & \multicolumn{2}{|c|}{ Type $1(n=23)$} & \multicolumn{2}{|c|}{ Type $2(n=59)$} & \multirow[t]{2}{*}{ Statistics } \\
\hline & No. & $\%$ & No. & $\%$ & \\
\hline Sex & & & & & $\chi^{2}=0.76, \mathrm{df}=1, P>0.05$ \\
\hline Male & 12 & 52.2 & 37 & 62.7 & \\
\hline Female & 11 & 47.8 & 22 & 37.3 & \\
\hline Education & & & & & $\chi^{2}=5.28, \mathrm{df}=5, P>0.05$ \\
\hline Primary school & 3 & 13.0 & 10 & 16.9 & \\
\hline Junior high school & 4 & 17.4 & 19 & 32.2 & \\
\hline Senior high school & 9 & 39.1 & 16 & 27.1 & \\
\hline College & 2 & 8.7 & 1 & 1.7 & \\
\hline University & 5 & 21.7 & 13 & 22.0 & \\
\hline Marital status & & & & & $\chi^{2}=5.35, \mathrm{df}=6, P>0.05$ \\
\hline Single & 13 & 56.5 & 21 & 35.6 & \\
\hline Married & 6 & 26.1 & 27 & 45.8 & \\
\hline Divorced & 2 & 8.7 & 7 & 11.9 & \\
\hline Widowed & 2 & 8.7 & 4 & 6.8 & \\
\hline Employment status & & & & & $\chi^{2}=10, \mathrm{df}=4, P<0.03$ \\
\hline Unemployed & 7 & 30.4 & 10 & 16.9 & \\
\hline Full time employment & 8 & 34.8 & 26 & 44.1 & \\
\hline Student & 3 & 13.0 & 1 & 1.7 & \\
\hline Housewife & 5 & 21.7 & 12 & 20.3 & \\
\hline Early retirement due to psychiatric illness & - & - & 10 & 16.9 & \\
\hline
\end{tabular}




\begin{tabular}{|c|c|c|c|c|}
\hline \multirow[t]{2}{*}{ Psychiatric diagnosis } & \multicolumn{2}{|c|}{ Type 1 diabetes } & \multicolumn{2}{|c|}{ Type 2 diabetes } \\
\hline & No. & $\%$ & No. & $\%$ \\
\hline Schizophrenia & 12 & 52.2 & 25 & 42.4 \\
\hline Schizoaffective & 1 & 4.3 & 5 & 8.5 \\
\hline Major depression & 4 & 17.4 & 18 & 30.5 \\
\hline Bipolar II - depression phase & 1 & 4.3 & 2 & 3.4 \\
\hline Bipolar II - mania phase & 5 & 21.7 & 9 & 15.3 \\
\hline
\end{tabular}

diabetes" where psychotropic medication may further increase the risk of the development diabetes, either directly or as a result of iatrogenic weight gain [2]. This issue has been the focus of much recent research [12,20-22]. Literature supports an association between the use of antipsychotic medication and impaired glucose metabolism, however methodological weaknesses abound and prospective randomized trials are required [23].

Given that type 1 diabetes was once called 'juvenile diabetes', it was not surprising that type 1 diabetics in the present study were significantly younger than type 2 diabetics. This factor may explain many of the significant findings in contrasting type 1 and type 2 diabetics. Type 1 diabetics characteristically have an onset earlier in their life span than type 2, have a greater tendency for the need for insulin at an earlier age and have a shorter life expectancy. As a consequence of the vicissitudes of their illness, it is perhaps understandable that type 1 diabetics may experience obstacles in pursuing relationships, marriage, education and employment. This finding adds weight to the assertion made by other researchers that type 1 young diabetic patients should be seen more as a high-risk group for psychiatric disorders than the patients of most other chronic medical conditions [1].

\section{Predictors of outcome of psychiatric illness}

There was no significant difference in the course of psychiatric illness over a 2-year follow-up period between those with type 1 or type 2 diabetes, as indicated by the non-significant difference in the number of psychiatric rehospitalizations.

The existence of diabetes mellitus (regardless of type), the duration of untreated mental illness and the lack of patient therapeutic education were negative predictors of outcome in the present study. Given that comorbidity of disorders adds to treatment complexity and is frequently associated with chronicity [24], it is not surprising that diabetes negatively affects the course of psychiatric disorder.

Diabetes affects all aspects of everyday life and diabetics bear much of the responsibility for treatment decisions that will affect their immediate and long-term health but less than half of our patients had been exposed to therapeutic patient education and psychoeducational interventions. Therapeutic patient education aims to inform patients adequately about their chronic disorders in order to manage and take responsibility for their condition. Psychotherapeutic patient education can help patients to deal with the insecurity they suffer from and give the appropriate answers to their questions. Such education has brought about a significant decrease in the number of hospital admissions of patients with diabetic coma [25]. In the present study, a lack of therapeutic patient education was related to poor outcome of mental illness.

\begin{tabular}{lccc}
\hline Table 4 Regression analysis for variables predicting & & \\
\hline Variable & Unstandardized coefficient & Standardized coefficient \\
& B & SE & Beta \\
Sex & 4.80 & 2.88 & 0.05 \\
Diagnosis & 0.24 & 0.83 & 0.00 \\
Age at onset of psychiatric symptoms & -6.59 & 0.17 & -0.00 \\
Duration of untreated mental illness & -1.99 & 0.39 & $-0.15^{* *}$ \\
Marital status & -0.46 & 1.31 & -0.1 \\
Psychoeducation & 43.5 & 2.87 & $0.48^{* *}$ \\
Diabetes mellitus & -0.10 & 0.04 & $-0.06^{*}$ \\
\hline
\end{tabular}

${ }^{*} P<0.05 ;{ }^{*} P<0.01$.

${ }^{a}$ Outcome (dependent) variable $=$ number of months after treatment that the patient relapsed .

$S E=$ standard error. 
A large proportion of our patients (41.4\%) in our study were non-compliant with psychiatric treatment. Interestingly, $25.4 \%$ adhered to diabetic treatment (regular visits to the diabetologist and controlled blood glucose levels) but were non-compliant with their psychiatric treatment after discharge from the psychiatric unit. The fact that patients compliant with diabetes treatment were not always compliant with psychiatric treatment may be because of be denial of a psychiatric disorder in order to avoid stigmatization. Research evidence suggests that stigma has a significant effect on the lives of people with mental illness [26]. There is no stigma associated with high blood pressure or diabetes, but there is stigma associated with being mentally ill [26].

The significance of the duration of untreated mental illness, the third negative predictor of outcome, concurs with the vast majority of studies that have correlated early treatment with better outcome [27]. In our study, the duration of untreated mental illness was shorter for type 1 diabetics n compared with type 2 patients. Again, stigma may prevent people from seeking immediate professional intervention and consequently increase the duration of untreated psychosis, which has a negative impact on the course of the chronic disease [28].

\section{Limitations}

The present study was limited by the fact that the sample comprised of psychiatric inpatients only. Thus our findings relate to patients suffering more severe forms of psychiatric illness as the participants comprised those admitted, involuntarily in many cases, to a psychiatric hospital. A more representative sample of psychiatric patients would also include outpatients.

Certain crucial variables, such as the onset of psychiatric illness, could not be measured by standardized instruments. Such variables were assessed by the clinical team and were based on patient and family member reports and records of treating facilities.

\section{Clinical implications}

The proportion of diabetes as the comorbid condition in our psychiatric population was almost 3 times higher than that expected in the general population $[1-3,19]$. Although there is significant variation in the comorbid prevalence of diabetes in psychiatric patients, this prevalence is consistently higher than would be expected in the general population.

Psychiatric patients with comorbid type 1 diabetes had a differential profile than those with comorbid type 2 diabetes. Type 1 diabetics tended to be younger at age of onset of the psychiatric disorder, single, have a diagnosis of either schizophrenia or bipolar II (manic phase). Type 1 diabetes typically preceded mental illness by less than 6 months. Type 2 diabetics tended to be older at age of onset of the psychiatric disorder, were married and had a diagnosis of schizophrenia or depression.

There was no significant difference in the outcome of the psychiatric disorder in patients with type 1 or type 2 diabetes as the comorbid condition. The existence of diabetes mellitus (regardless of type) and the duration of untreated mental illness were negative predictors of (unfavourable) outcome psychiatric disorders while provision of patient therapeutic education was positive predictor of (favourable) outcome.

\section{References}

1. Blanz BJ et al. IDDM is a risk factor for adolescent psychiatric disorders. Diabetes Care, 1993, 16:1579-1587.

2. Cassidy F, Ahearn E, Carroll BJ. Elevated frequency of diabetes mellitus in hospitalized manic-depressive patients. American Journal of Psychiatry, 1999, 156:1417-1420.

3. Mukherjee $S$ et al. Diabetes mellitus in schizophrenic patients. Comprehensive Psychiatry, 1996, 37:68-73.

4. Regenold WT et al. Increased prevalence of type 2 diabetes mellitus among psychiatric inpatients with bipolar I affective and schizoaffective disorders independent of psychotropic drug use. Journal of Affective Disorders, 2002, 70:19-26.

5. Ruzickova $\mathrm{M}$ et al. Clinical features of bipolar disorder with and without comorbid diabetes mellitus. Canadian Journal of Psychiatry, 2003, 48:458-461.

6. Shaw E, Sicree RA, Zimmet PZ. Global estimates of the prevalence of diabetes for 2010 and 2030. Diabetes Research and Clinical Practice, 2010, 87:4-14

7. Rubin RR et al. Recognising and treating depression in patients with diabetes. Current Diabetes Reports, 2004, 4:119-125.

8. Lustman PJ, Anderson R. Depression in adults with diabetes. Psychiatric Times, 2002, 19:45-48.
9. Lustman PJ et al. Effects of nortriptyline on depression and glycemic control in diabetes: results of a double-blind, placebocontrolled trial. Psychosomatic Medicine, 1997, 59:241-250.

10. Maudsley H. The physiology and pathology of the mind. London, Macmillan, 1867.

11. Lindenmayer J-P et al. Changes in glucose and cholesterol levels in patients with schizophrenia treated with typical or atypical antipsychotics. American Journal of Psychiatry, 2003, 160:290-296.

12. Sernyak MJ et al. Association of diabetes mellitus with use of atypical neuroleptics in the treatment of schizophrenia. American Journal of Psychiatry, 2002, 159:561-566.

13. Dinan T. Schizophrenia and diabetes 2003: an expert consensus meeting: Introduction. British Journal of Psychiatry, 2004, 184(Suppl. 47):S53-S54.

14. Diagnostic and statistical manual of mental disorders, 4th ed. Washington DC, American Psychiatric Association, 1994.

15. Craig TJ et al. Is there an association between duration of untreated psychosis and 24-month clinical outcome in a first-admission series? American Journal of Psychiatry, 2000, 157:60-66. 
16. Lee AS, Murray RM. The long-term outcome of Maudsley depressives. British Journal of Psychiatry, 1988, 153:741-751.

17. Carpenter WT et al. Decisional capacity for informed consent in schizophrenia research. Archives of General Psychiatry, 2000, 57:533-538.

18. Stroup S et al. Decision-making capacity for research participation among individuals in the CATIE schizophrenia trial. Schizophrenia Research, 2005, 80:1-8.

19. Goodnick P. Treatment of depression in patients with diabetes mellitus. Journal of Clinical Psychiatry, 1995, 56(4):128-36.

20. Buse JB et al. A retrospective cohort study of diabetes mellitus and antipsychotic treatment in the United States. Journal of Clinical Epidemiology, 2003, 56:164-170.

21. Koro CE et al. Assessment of independent effect of olanzapine and risperidone on risk of diabetes among patients with schizophrenia: population based nested case-control study. BMJ (Clinical Research Ed.), 2002, 325:243-248.

22. Lambert B et al. Assessing the risk of antipsychotic-induced type II diabetes among schizophrenics: a matched case control study. European Neuropsychopharmacology, 2002, 12(Suppl. 3):S307-S308.
23. Bushe C, Leonard B. Association between atypical antipsychotic agents and type 2 diabetes: review of prospective clinical data. British Journal of Psychiatry, 2004, 184 (Suppl. 47):S87-S93.

24. Evans K, Sullivan JM. Dual diagnosis: counseling the mentally ill substance abuser. New York, Guilford Press, 1990.

25. Global burden of disease. Geneva, World Health Organization, 1990.

26. Mental health care. The Institute of Psychiatry, South London and Maudsley NHS Foundation Trust, Rethink, The Wellcome Trust [webpage]. Discrimination and stigma (http://www.mentalhealthcare.org.uk/discrimination_and_stigma, accessed 6 September 2011).

27. Waddington JL et al. Course of psychopathology, cognition and neurobiological abnormality in schizophrenia: developmental origins and amelioration by antipsychotics? Journal of Psychiatric Research, 1998, 32:179-189.

28. Jackson C, Birchwood M. Early intervention in psychosis: opportunities for secondary prevention. British Journal of Clinical Psychology, 1996, 35:487-502.

\section{Mental health and development: targeting people with mental health conditions as a vulnerable group}

People with mental health conditions have been excluded from the development agenda despite being a marginalized and vulnerable group in countries all over the world. This report, Mental health and development: targeting people with mental health conditions as a vulnerable group, highlights the urgent need to redress this situation. It presents compelling evidence that people with mental health conditions meet major criteria for vulnerability and yet fall through the cracks of development aid and government attention. It makes the case for reaching out to this vulnerable group through the design and implementation of appropriate policies and programmes and through the inclusion of mental health interventions into broader poverty reduction and development strategies. It also describes a number of key interventions that can provide a starting point for these efforts. The report is a call to action to all development stakeholders - multilateral agencies, bilateral agencies, global partnerships, private foundations, academic and research institutions, governments and civil society - to focus their attention on mental health. By investing in people with mental health conditions, development outcomes can be improved.

Further information about this and other WHO publications is available at: http:/ /www.who.int/publications/en/ 